\title{
Um olhar sobre a realidade de Moçambioue: a enfermagem e a saúde
}

\author{
A closer look at the Mozambique reality: nursing and health \\ Una mirada sobre la realidad de Mozambieue: enfermería y salud
}

\author{
Ana Paula Faustino Gilio', Genival Fernandes de Freitas ${ }^{1}$ \\ 'Universidade de São Paulo, Escola de Enfermagem. São Paulo, SP
}

Submissão: 02/08/2006

Aprovação: 13/07/2007

\begin{abstract}
RESUMO
A identidade e a memória da Enfermagem são feitas por meio inserção histórica, política e social dos enfermeiros e de suas associações de classe, na busca e fortalecimento dos valores profissionais. Nessa ótica, o presente estudo tem como objetivos compartilhar com os profissionais de enfermagem e os estudantes dessa área algumas vivências e impressões acerca das realidades sócio-política e de saúde na República Popular de MoçambiQue, bem como a atuação dos profissionais de enfermagem naQuele país, dificuldades e coneuistas, e contribuir para um processo reflexivo acerca do reconhecimento social da enfermagem.
\end{abstract}

Descritores: História de Enfermagem, Saúde, Enfermagem.

\section{ABSTRACT}

Identity and memory of Nursing are built through studies on historical, political and social aspects of the profession and its collective organizations searching to strengthening its values. In this view, goals of this study are: to share with nursing professionals and students an experience of visiting Mozambioue and collecting some information on social, political, health and living conditions of people within this country; and, to disseminate this experience among nurses and colleagues in order to stimulate similar very enriching learning opportunities.

Descriptors: History of nursing, Health, Nursing.

\section{RESUMEN}

La identidad y la memoria de la Enfermería se hace a traves de estudios de los aspectos históricos, políticos y sociales de la profesión y sus organizaciones colectivas en la búsqueda de fortalecer sus valores. Dentro de esta visión, los objetivos de este estúdio son: compartir con los profesionales y estudiantes una experiência de visitar MozambiQue y recojer algunas informaciones sobre las condiciones sociales, políticas y de vida del pueblo dentro de este país; y, diseminar esta experiência entre los enfermeros y colegas a fin de estimular oportunidades similares de un muy rico aprendizage.

Descriptores: Historia de la enfermería, Salud, Enfermería.

\section{INTRODUÇÃO}

A motivação para conhecer a História de MoçambiQue e a atuação dos profissionais de enfermagem daQuele país despontou, em 2005, por ocasião do ingresso no curso de graduação da Escola de Enfermagem da Universidade de São Paulo, a partir da realização do módulo sobre História da Enfermagem brasileira e mundial, o qual é ministrado pelo co-autor deste texto. Nesse módulo, foi feita uma retrospectiva da ação da enfermagem em diversas culturas do mundo, inclusive mencionado Que um enfermeiro havia se tornado Presidente da República em Moçambieue, um país localizado na costa sudoeste da África e de língua Portuguesa. Dois fatores concorreram para o interesse em visitar MoçambiQue: a minha mãe fazia consultoria jurídica ao governo moçambicano e o fato de uma docente da disciplina de História de Enfermagem da USP ter trabalhado na Organização Internacional de Enfermagem, inclusive ter conhecido e

Correspondência: Ana Paula Faustino Gilio. Av. Dr. Enéas de Carvalho Aguiar, 419. Cerqueira César. CEP - 05403-000 - São Paulo, SP. 
mantido contactos com líderes da enfermagem moçambicana. Com isso, foi possível intermediar entrevistas com algumas daquelas líderes e visitar instituições moçambicanas voltadas para a saúde e a educação em enfermagem. A possibilidade de visitar MoçambiQue tornou-se realidade no início de 2006.

Em visita a Maputo, capital de MoçambiQue, no período de 23 de janeiro a 17 de fevereiro de 2006, pude conversar e entrevistar a presidente da Associação Nacional de Enfermeiros Moçambicanos (ANEMO), a enfermeira Lídia Mondlane e uma outra líder e membro dessa Associação ( a enfermeira Margarida BuQue), as Quais me acompanharam para uma visita ao Hospital Central, Que é o maior hospital daquela cidade e centro de referência para o encaminhamento de pacientes mais graves. Pude observar a realização de atendimentos aos pacientes, por parte dos profissionais de saúde e, especialmente dos profissionais de enfermagem. Tive também a oportunidade de acompanhar alguns serviços de enfermagem no Hospital de Dia do Hospital Militar de Maputo, onde eram atendidos pacientes Que viviam com HIV/SIDA.

Embora MoçambiQue tenha sido descoberto em 1498, por Vasco da Gama, só em 1885, com a divisão da África entre os colonizadores europeus durante a Conferência de Berlim, houve a penetração portuguesa por meio de ocupação militar e submissão dos estados africanos existentes na época. Assim, a partir da década de 1950, eclodem movimentos nacionalistas na África, tendo sido criada a Frente de Libertação de MoçambiQue (Frelimo), em 1962, cujo lema era marxista e teve líderes nacionais lembrados até hoje como Eduardo Mondlane (Que foi assassinado em 1964) e Samora Machel, Que o substituiu e tornou-se o primeiro Presidente da República negro e enfermeiro na História. Além de político, sua vida de dedicação pela independência daQuele país e pela luta e busca de melhorias nas condições de vida e saúde da população, tornando-se não só em um herói nacional Moçambieue, mas um exemplo de perseverança e conQuistas pelo reconhecimento social e político da profissão ${ }^{(1)}$.

São objetivos deste trabalho compartilhar com os profissionais de enfermagem e os estudantes algumas vivências e impressões acerca da realidade social e de saúde na República Popular de MoçambiQue, bem como a atuação dos profissionais de enfermagem naquele país, dificuldades e conquistas, e contribuir para um processo reflexivo a partir dessas experiências.

Isto posto, passaremos a discorrer sobre alguns dados da realidade de saúde, educação e política de Moçambieue, um breve histórico sobre a figura lendária de Samora Machel, o papel da Associação Nacional de Enfermeiros de Moçambieue, apontando para a necessidade de parceirização e diálogo entre o Brasil e MoçambiQue em diversas áreas, mormente da saúde e educação.

\section{UM OLHAR SOBRE MOÇAMBIQUE}

O Jornal da USP destacou, em uma matéria recente sobre Brasil e Moçambique, diálogo necessário, a parceria entre professores da USP e de MoçambiQue com o escopo de promover a alfabetização de crianças, jovens e adultos dauuele país. Para tanto, encontra-se planejada a realização da primeira missão de trabalho a Maputo, para conhecer a realidade local e as práticas pedagógicas cotidianas ${ }^{(2)}$.

MoçambiQue tornou-se independente de Portugal em 1975 e possui uma superfície territorial de $799.390 \mathrm{Km} 2^{(3)}$. Segundo dados do Instituto Nacional de Estatística ${ }^{(4)}$ e UNICEF ${ }^{(5)}$, o país tem uma população de, aproximadamente, 20 milhões de habitantes, sendo Que deste contingente cerca de $37 \%$ vivem na zona urbana. Há taxas de natalidade de 769 mil nascimentos/ano, mortalidade infantil (por 100) de 154 para homens e 163 para mulheres, esperança de vida ao nascer de 44 homens e 46 mulheres e expectativa de vida saudável ao nascer de 36,3 para homens e 37,5 para mulheres, segundo dados da $\mathrm{OMS}^{(6)}$.

A taxa de analfabetismo dos maiores de 15 anos girava em torno de 54,6\%, no último levantamento feito em 2003. Menos de $8 \%$ da população maior de 15 anos havia concluído o ensino primário. O país está em septuagésimo lugar no ranking mundial de pobreza, segundo o Índice de Desenvolvimento Humano de 2004, com uma renda per capita de 210 dólares, comparada com 450 dólares da África-Sub-Saariana ${ }^{(7)}$.

O país tem feito um progresso econômico notável desde o final da Guerra Civil em 1992, com a economia crescendo em $8 \%$ ao ano. A proporção de famílias vivendo abaixo da linha da pobreza total (falta de rendimentos necessários para satisfazer necessidades alimentares básicas ou requisitos calóricos mínimos) diminuiu de 69,4\% em 1996-97 para 54,1\% em 2002-03. Esta melhoria aparenta ter-se verificado mais nas zonas rurais, onde também, a pobreza era (e permanece) mais freqüente. Mais de $50 \%$ da população vive com menos de 2 dólares por pessoa por $\operatorname{dia}^{(7)}$.

Em relação à situação da mulher, vê-se Que o acesso desigual aos recursos, o analfabetismo, a dependência econômica e as desigualdades de poder e autoridade na família, na comunidade e na sociedade em geral, reforçam a subordinação da mulher, reduzindo a possibilidade desta participar igualmente em assuntos referentes à sua própria vida. A sexta-feira é considerada o Dia do Homem, Quando o homem está livre para sair de casa e só voltar no domingo, sem obrigação alguma de prestar contas à família. É comum Que os homens mantenham relações extraconjugais. A violência doméstica é freqüente, até mesmo as mulheres acham correto Que a esposa apanhe por desobedecer ao marido ${ }^{(7)}$.

\section{A REALIDADE DE SAÚDE EM MOÇAMBIQUE}

Existe no País uma crença muito forte nos chamados "médicos tradicionais". Na medicina tradicional, a concepção de saúde e doença é bastante diferente daQuela do modelo biomédico. A doença é fruto não só de um desequilíbrio físico, mas também de uma disfunção das relações entre o ser humano, o meio social, o meio ambiente e os antepassados. Acredita-se Que os antepassados continuam a fazer parte da vida da comunidade. Na medicina tradicional, as doenças são classificadas e divididas de duas formas: 1) aQuelas causadas por condições biofísicas/naturais Que podem ser resolvidas pelos membros mais velhos da comunidade Que possuem conhecimento para curar a doença; 2) doenças provocadas pela intervenção de forças maléficas Que exigem um tratamento mais complexo, pois necessitam da ajuda dos espíritos dos antepassados e da comunicação com entidades sobrenaturais.

Devido a natureza do seu trabalho, os praticantes de medicina tradicional são em grande regra, bastante respeitados e influentes na comunidade. O médico tradicional geralmente assume o papel de guardião de valores, até porQue este pode combinar a função de líder religioso e comunitário. Em novembro de 2004, foram 
estimados mais de 72.000 médicos tradicionais, comparados com cerca de 500 médicos em todo o país ${ }^{(8)}$. As causas de morte mais expressivas no país são: tuberculose, malária, HIV/AIDS (Vírus da Imunodeficiência AdQuirida/Síndrome da Imunodeficiência AdQuirida), cólera e outras doenças diarréicas. Em relação à contaminação por HIV, segundo estimativas do Instituto Nacional de Estatística (INE), a taxa de prevalência entre as pessoas com 15 e 49 anos de idade agora está nos 15,6\%, comparando com os 8,2\% em 1998 .Mais de um milhão de crianças e jovens com idade inferior a 18 anos ou vivem com o vírus, ou cuidam dos seus pais ou outros familiares próximos sofrendo de doenças causadas pela AIDS, ou ainda perderam o seu pai ou a sua mãe com esta pandemia. Mais de 400.000 crianças estão órfãs e vulneráveis. Estima-se que cerca de $60 \%$ dessas crianças estão orfãs devido ao AIDS. Esta situação continua aumentando de maneira alarmante e estima-se Que em 2010, o número de orfãos devido ao HIV/AIDS seja em torno de $500.000^{(7)}$.

Em 2003, $41 \%$ das crianças moçambicanas com menos de 5 anos de idade sofria de desnutrição crônica, esse caso vem se agravando ao longo dos anos; em 1997 36\% das crianças com menos de 5 anos sofria de desnutrição crônica $^{(7)}$.

Crianças com menos de 5 anos com diarréia Que recebem hidratação e alimentação adeQuada e continuada durante a doença: $46 \%{ }^{(5)}$.

Existe um grande número de ONG's internacionais Que apóiam diversos setores da saúde, algumas assumem medidas de resolução momentânea, como a vinda de profissionais da saúde de outros países para atender a falta de pessoal, e outras adeuirem o papel de ajuda no desenvolvimento das unidades sanitárias através de medidas administrativas, financeiras e pedagógicas.

Em 200 I , a maior parte da população possuía casa própria. Grande parte da população moçambicana (54\%) utiliza como energia para iluminação o petróleo/gás e $7 \%$ utiliza energia elétrica. Sendo Que apenas 1\% do meio rural utiliza eletricidade, contra $21 \%$ do meio urbano.(2003). Para cozinhar no meio rural, cerca de $96 \%$ da população utilizava lenha e $1 \%$ utilizava eletricidade. No meio urbano, a porcentagem da população Que utilizava lenha era de $10 \%$.

Estimou-se, em 2003, Que cerca de 55\% da população vive em casas sem instalações sanitárias e sem latrinas, o Que representa um peQueno progresso em relação à 2001 (58\%) e apenas uma minoria da população (16\%) tinha acesso à água potável canalizada, enQuanto $20 \%$ utilizavam água de poços protegidos, $42 \%$ de poços não protegidos e $16 \%$ usavam águas superficiais ${ }^{(5)}$. A coleta de lixo nas ruas não é suficiente, deixando os locais, principalmente os centros urbanos, cheios de lixo transbordando por vários dias ${ }^{(7)}$.

\section{A REALIDADE DA ENFERMAGEM E A ASSOCIAÇÃO NACIONAL DOS ENFERMEIROS DE MOÇAMBIQUE (ANEMO)}

Essa experiência possibilitou uma aproximação com algumas enfermeiras daquele País, a fim de conhecer a inserção da enfermagem e o seu papel na sociedade, na promoção e restabelecimento da saúde dos cidadãos. As enfermeiras Matilde Basílio (Presidente da ANEMO) e Margarida Buque (membro da ANEMO e coordenadora do Departamento de Cuidados
Domiciliários), ao serem indagadas sobre a inserção da enfermagem no sistema de saúde daQuele país nos disseram que ressaltavam algumas problemáticas como o déficit de recursos humanos em saúde e de materiais básicos para o atendimento das necessidades da coletividade. Referiram também a dificuldade delas em atualizar seus conhecimentos na área de enfermagem.

Cabe ressaltar, ainda, Que logo após a libertação de Moçambieue do domínio português, em 1975, houve um êxodo dos enfermeiros para Portugal e estabeleceu-se a premente necessidade de recrutamento de candidatos para exercerem atividades de enfermagem, sendo feita a seleção de pessoas não Qualificadas para o cuidado, acarretando uma piora do atendimento e da assistência prestada. A partir de então, percebeu-se uma diminuição do reconhecimento e aceitação dos enfermeiros pela população, porQue a percepção das pessoas era a de Que o "enfermeiro" era Qualquer pessoa semi-alfabetizada. Havia uma dificuldade de identificação entre as pessoas Que atuavam no âmbito da saúde, o Que contribuiu para Que o trabalhador sem QualQuer Qualificação, aproveitando-se da situação confusa e das novas estruturas sóciopolíticas no período pós-independência, Quisesse sobrepor-se ao profissional enfermeiro.

O período de 1979 a 1983 foi chamado de "período negro" da história da enfermagem moçambicana, caracterizado pela má Qualidade dos cuidados de enfermagem. A falta de recursos para a consecução das ações de saúde, associada às dificuldades Que o país atravessava (devido a Guerra Civil), agravaram a situação da enfermagem, sobretudo pelo aumento da demanda devido à guerra e a deficiência estrutural para atender a todos.

Alguns médicos ignoravam totalmente as tarefas do enfermeiro, a ponto de pensar Que cada medico teria um enfermeiro como ajudante, um "Serve de Bata Branca". O enfermeiro não era considerado um membro da equipe do Sistema Nacional de Saúde com tarefas bem definidas e distintas.

O baixo nível de formação dos enfermeiros no período pósindependência repercutiu na enfermagem por muitos anos. E só na década de 80, com a fundação da ANEMO (Associação Nacional dos Enfermeiros de Moçambique) é que a enfermagem começou a conQuistar ideais como a elevação do nível de conhecimentos, a estabilidade de programas de formação, melhoramento dos meios de trabalho, recursos e adeQuação salarial.

Apesar dos avanços da enfermagem com a fundação da ANEMO, a Qualidade dos cuidados de enfermagem ainda tem muito Que ser coneuistada. Isso se deve a diversos fatores como a melhoria da capacitação dos recursos humanos em enfermagem, materiais e bens financeiros, bem como a Questão da biossegurança e das condições sociais, relativas à saúde, educação e habitação, tanto para os enfermeiros, Quanto da população em geral.

Até 2003, a formação do enfermeiro baseava-se apenas em cursos profissionalizantes Que não exigiam Que a pessoa tivesse concluído o segundo grau. A partir daquele ano, teve inicio o primeiro curso de enfermagem de nível superior e a primeira turma irá se formar em 2006, na Universidade Eduardo Mondlane.

Até hoje no país só existem 14 enfermeiros de nível superior formados em Moçambique, estes se formaram em uma universidade particular Que foi criada pelo governo, mas logo depois de formada a primeira turma não deu mais continuidade ao curso.

Os profissionais de saúde responsáveis pelo atendimento à 
população são: o enfermeiro elementar, o enfermeiro básico, o enfermeiro médio, o enfermeiro geral, o agente de medicina, o técnico de medicina e o médico. Segundo as enfermeiras da ANEMO, o chamado "enfermeiro elementar" é o trabalhador menos qualificado formalmente, porQue não possui nenhuma formação específica na enfermagem. Já o "enfermeiro básico e o médio" são mais executantes das ações de enfermagem, e possuem uma formação de maior duração, indo de um a dois anos, e o "enfermeiro geral" é o Que supervisiona, delega e gerencia as atividades de enfermagem, com uma formação mais prolongada de dois a três anos.

A enfermagem é dividida em muitos níveis de formação e, em função da grande demanda de pacientes e da falta de pessoal, é cobrada capacitação e desenvoltura de todas as categorias de enfermagem para atender à demanda dos serviços, já Que a Quantidade de enfermeiros formados é extremamente insuficiente naquele país. Isso é um problema sentido e referido pelos enfermeiros da ANEMO, pois referem Que a capacitação técnica Que se exige desses profissionais é a mesma para todos, independente da formação possibilitada nos níveis elementar, básico, médio ou geral.

A categorização da enfermagem em tantos níveis, mesmo Que todos exerçam a mesma função, banaliza os profissionais com menor "título", com baixo reconhecimento e baixa remuneração salarial.

Por outro lado, a falta de médicos no país induziu a profissão de enfermagem a aderir a um papel muito importante no atendimento aos pacientes. A enfermagem faz Quase tudo, o enfermeiro atende, prescreve, faz triagem e dá alta. Existem regiões em Que a falta de medico é absoluta, o Que levou a construção das chamadas "Casas do Enfermeiro", onde o enfermeiro é o maior responsável pelo atendimento. Ainda assim, o pessoal de enfermagem também é limitado, e não consegue atender a todos os pacientes.

A assistência ao paciente torna-se comprometida também pela falta crônica de materiais e equipamentos básicos como seringas, agulhas, termômetros, aparelhos de pressão, anti-sépticos, medicamentos, luvas, leitos, etc. Ainda existem relatos de locais Que utilizam seringas de vidro para cuidados de enfermagem.

A deficiência de materiais e a falta de instrução dos trabalhadores para cuidarem de si mesmos comprometem a saúde ocupacional, tornando-os mais vulneráveis no desempenho das ações de saúde, expondo-os a situações de perigo de disseminação das doenças, sobretudo devido à falta de saneamento básico e até mesmo de água potável para servir os doentes ou lavar as mãos.

A maioria dos profissionais de enfermagem é proveniente de regiões mais periféricas, o Que facilita muitas vezes a comunicação com os pacientes Que não falam português, somente dialetos. Por outro lado, o fato destes profissionais morarem em regiões tão distantes, torna-os dependentes do transporte público, Que é muito precário e demorado.

O salário dos enfermeiros é muito baixo e, muitas vezes, eles são compelidos a cumprirem jornadas duplas de trabalho sem ter sequer o Que comer até que cheguem em casa.

Durante a visita aos hospitais em Maputo (capital de Moçambique), percebeu-se um desânimo dos trabalhadores de enfermagem em função das condições sociais, impedindo a motivação e o desempenho profissional desses sujeitos.

Entretanto a enfermagem em Moçambieue tem realizado grandes esforços e até conQuistado algum reconhecimento social, com o ressurgimento do curso de nível superior em Enfermagem, bem como a criação da ANEMO e a participação dessa entidade de classe junto ao Conselho Internacional de Enfermeiras (CIE) e a vinculação da mesma com o Ministério da Saúde daQuele país. Percebe-se Que ainda há muito o Que se fazer, mas os primeiros passos já foram dados.

Nesse sentido, convém lembrar que o reconhecimento e a valorização da enfermagem é um sonho dos enfermeiros, devendo ser alcançados por meio da atividade política dos enfermeiros, da inserção nas atividades de classe, enQuanto cidadãos cientes do seu papel na sociedade e da coneuista dos espaços e dos seus direitos.

\section{CONSIDERAÇÕES FINAIS}

A enfermagem moçambicana, assim como muitas outras profissões daquele país, está se desenvolvendo e se levantando de um longo período de dificuldades em razão da recente independência. Embora existam poucos enfermeiros na atualidade, percebe-se Que a motivação de formar novos enfermeiros torna-se mais viável graças a criação de uma instituição de ensino superior em enfermagem no país.

Não há como falar da enfermagem sem contextualizá-la em meio à cultura, à historia política, às condições sociais e econômicas. Assim, a precariedade das condições de vida e saneamento básico em Moçambique têm propiciado o adoecimento de grande parcela da população, e o atendimento de saúde é um reflexo destes fatores.

Num país em que a pobreza, a fome, as dificuldades habitacionais e as doenças são tão constantes, a melhoria da capacitação do pessoal de enfermagem é essencial, tendo em vista Que a falta de profissionais de saúde, torna a assistência de enfermagem mais relevante ao minimizar os sofrimentos da população mais carente, possibilitando o atendimento das necessidades de saúde mais primárias.

A enfermagem em MoçambiQue vem se estruturando, criando uma identidade e um papel no plano de saúde do país. Nessa perspectiva, vê-se Que o envolvimento dos enfermeiros em atividades políticas valorizou um pouco mais a atuação e o papel desses profissionais no cenário da saúde, desde a época de Samora Moisés Machel, Que foi um grande líder e herói nacional, primeiro e único enfermeiro Que se tornou em um presidente da República Popular de Moçambieue.

Após uma visita ao Hospital Militar de Maputo, foi possível presenciar o encontro de pacientes e profissionais de saúde, Que ao final deram-se as mãos e cantaram essa canção, tanto em português, como em dialeto (xangana - dialeto típico do sul de Moçambique): "Sonho que se sonha só, é só um sonho Que se sonha só, mas sonho Que se sonha junto é realidade...". 


\section{REFERÊNCIAS}

1. Sopa A, organizador. Samora: Homem do povo. Maputo (MOZ): Mabuko; 2001 .

2. Silva N, Mutimucuio I, Nandja D. Brasil e Moçambieue, diálogo necessário. J Universidade de São Paulo 2006; 26: 2.

3. Moçambique na Internet. Dados básicos. [citado em: $10 \mathrm{dez}$ 2005]. Disponível em: URL: http://www.mozambique.mz/

4. Instituto Nacional de Estatística de Moçambique. [citado em: 10 dez 2005]. Disponível em: URL: http://www.ine.gov.mz/

5. United Nations Children's Fund. Statistics. [cited on: $2006 \mathrm{feb}$ 3]. Available at: URL: http://www.unicef.org/infobycountry/ mozambiQue.html
6. World Health Organization (WHO). Countries. Mozambieue [cited on 2005 dec 2 I] . Available at: URL: http://www.who.int/en/

7. Ministério da Saúde (MOZ). Conselho Nacional de Combate ao HIV/SIDA: Plano Estratégico Nacional de Combate ao HIV/ SIDA: 2005-2009. Maputo (MOZ): Ministério da Saúde; 2004.

8. Ministério da Saúde (BR). Programa Nacional de DST e AIDS. Documentos e publicações. Busca por documentos. MoçambiQue. Matéria 21-06-05 Ministério da Saúde lança 10 reportagens sobre aids em Moçambique.doc. Um panorama da Aids em Moçambieue. Brasília (DF): Ministério da Saúde; 2005. 